\title{
Análise semiótica do poema "En la humedad cifrada", de Coral Bracho
}

\author{
Natália Cipolaro GUIRADO \\ (Universidade de São Paulo)
}

RESUMO: Este artigo propõe uma análise semiótica do poema "En la humedad cifrada", de Coral Bracho, que pertence à poesia Neobarroca da América Latina. A construção do sentido do poema será demonstrada mediante o percurso gerativo de sentido com enfoque na tematização e figurativização.

PALAVRAS-CHAVE: polissemia; tematização; figurativização; poesia; neobarroco

\begin{abstract}
This article proposes an analysis of the poem "En la humedad cifrada" by Coral Bracho, which belongs to the Latin America Neobarroco poetry. The poem's meaning construction will be shown by the generative process of meaning with focus on thematization and figurativization.
\end{abstract}

KEYWORDS: polysem; thematization; figurativization; poetry; neobarroco 


\section{A POESIA NEObARRoCA DA AMÉriCA LATINA}

A linguagem da poesia Neobarroca é experimental, renuncia o sentido denotativo das palavras e o enunciado linear de modo a buscar uma sintaxe diferenciada e distorcida com a enumeração caótica de elementos lingüísticos

É a poesia da busca pelo primitivo por meio da justaposição de elementos heterogêneos e pela colocação em pauta do tema do fingimento do poeta e é na linguagem que a ambigüidade do humano se refletirá.

Apesar do período estilístico Barroco ter sido criticado pela abundância de metáforas e hipérboles na Literatura, o intuito dos poetas do Neobarroco é conceber o poema como um jogo que tem fim em si mesmo, e então não há engajamento político como tema em sua produção, mas de outro modo, a busca por uma solução para a saturação que há no desgaste verbal contemporâneo.

\section{O PERCURSO GERATIVO DE SENTIDO}

\subsection{NÍVEL FUNDAMENTAL}

Analisando este poema no nível das oposições semânticas mínimas, é possível estabelecer a oposição semântica /vida/ e /morte/. O quadrado semiótico de análise oscilaria entre estes dois pólos, porém nesse corpus há a constante afirmação do valor de vida, como será demonstrado a seguir.

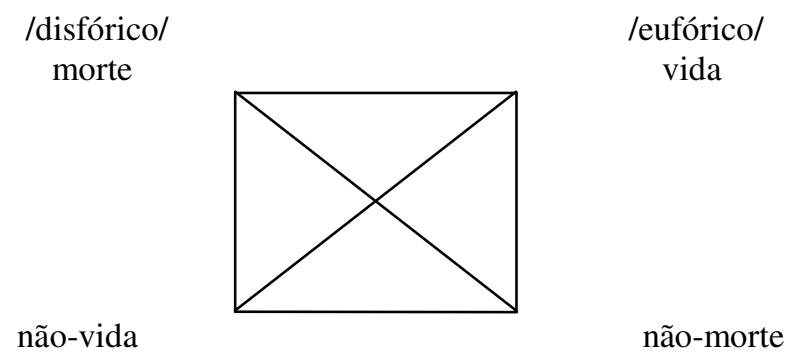

O valor de vida é euforizado durante todo o poema, conforme o sujeito busca o prazer. Então, há o surgimento do que estava oculto, como se houvesse um eixo vertical a ser seguido e a partir do qual há a imersão do homem "en la humedad cifrada". As palavras usadas para afirmar o valor de vida são muito recorrentes, como exemplo, "bullente", "brasas", "tíbios" que se referem ao calor, "fértil", "larvas", "fecundas" que se referem à fertilidade e "lascivas", "ebrias" que se referem à lascívia.

A sintaxe do nível fundamental também caminha para a afirmação da vida constantemente e visto que não há anti-sujeito, a narrativa torna-se acelerada, segundo a teoria do fazer missivo de Claude Zilberberg. Esta propõe que no nível figural do texto, o eu enunciativo é intersecção e arbitragem entre tempo e espaço, então, nos valores emissivos há a cronotrofia, o tempo diminui e o espaço se abre, pois a aceleração da narrativa faz com que o espaço descrito amplie-se. 


\subsection{NÍVEL NARRATIVO}

Visto que a narratividade é dada por uma transformação situada entre dois estados sucessivos diferentes, a sintaxe do nível narrativo deste poema pode ser compreendida como um trajeto para a aquisição do objeto de valor saciedade, percurso para aquisição de prazer por meio da imersão na umidade cifrada.

O início do coito faz com que o sujeito esteja seguro do êxito e da saciedade futura , está então no pólo de afirmação da vida. A avidez é adjetivada como paradoxal e a enunciação é praticada em momento incoativo em relação ao ato sexual.

Houve várias liquidações de privações à medida que o sujeito caminhou para entrar em conjunção com o objeto de valor saciedade, pois o homem estabelece contato físico com a amante e completa o desejo de cada um de seus sentidos citados "oigo", "bebo", "huelo", "toco". No final do poema, o sujeito entra em conjunção com o gozo, os "hervideros".

Pragmaticamente o sujeito está em contato com o objeto de valor, mas no âmbito cognitivo este é velado, visto que a relação entre eles é construída ao longo do poema.

Na manipulação, a primeira etapa da sintaxe deste nível de análise, o programa narrativo do poema pode ser sintetizado em uma formulação simbólica como esta: sujeito $U$ objeto de valor $\Rightarrow$ sujeito $\cap$ objeto de valor, em que o sujeito é o homem e o objeto de valor é a saciedade.

O que se observa não é apenas uma questão juntiva, de conjunção ou disjunção entre o sujeito e o objeto, mas também uma questão fiduciária entre os dois sujeitos na qual o contrato estabelecido não é rompido, pois não há quebra nas expectativas de ambos. O destinatário parece cumprir os desígnios do destinador e não há nada que obstrua o caminho para o estado final do sujeito em conjunção com o objeto de valor.

A competência é necessária ao sujeito para realizar a transformação central, sendo assim, neste poema observamos que o manipulador tem o poder fazer e o saber fazer para que a manipulada adquira querer fazer e se realize o programa narrativo.

Já na performance, que abarca a transformação central da narrativa, podemos observar o percurso do sujeito em busca do objeto de valor da saciedade, pois o homem tem sucesso na trajetória por meio da sedução que o corpo sinestésico lhe propõe.

$\mathrm{O}$ homem recebe da mulher informações sensuais que o convidam ao estímulo da audição, do paladar, do olfato e do tato. A sanção é a constatação de que a performance se realizou e, no corpus, esta se dá com o sucesso do sujeito na aquisição do objeto de valor, então, a obtenção do gozo é como a recompensa por seu trajeto, como um rito cíclico de cumprimento da sua missão.

A semântica do nível narrativo são os valores inscritos nos objetos modais e nos objetos de valor. Neste poema, os objetos modais "querer fazer" e "saber fazer" se referem ao desejo do homem de concretização de seu prazer sexual e o objeto de valor pelo qual o sujeito busca.

\subsection{NÍVEL DISCURSIVO}

Este é o nível de análise em que as formas abstratas do nível narrativo são revestidas de termos que lhe dão concretude. Deste modo, sua sintaxe apresenta a enunciação como 
produção do discurso, e a partir das marcas analisadas podemos identificar no poema uma debreagem enunciativa, pois há a projeção actancial do "eu", espacial do "aqui" e temporal do "agora" por meio da qual se estabelece uma relação de proximidade entre o enunciador e enunciatário.

A semântica deste nível de análise do percurso gerativo de sentido é composta por figuras, os termos que remetem àquilo que existe no mundo natural e também por temas, os investimentos semânticos que organizam os elementos figurativos.

Neste poema o tema do sexo não remete apenas à lascívia, mas à fecundidade $\mathrm{e}$ possibilidade de vida por meio dele, enquanto as figuras dos elementos da natureza, minerais e vegetais, e também os sentidos humanos são todos orientados por essa tematização de afirmação da vida, observamos então que é um texto figurativo, já que remete a um fato do cotidiano ao construir o simulacro de realidade.

Os lexemas "humedad cifrada" englobam o traço semântico da fertilidade existente na relação sexual e constroem essa isotopia no poema, pois ao longo do texto é retomado esse sentido, seja ao dizer sobre lascívia ou fecundação.

Este discurso desenvolve simultaneamente três isotopias: a prática, que é aquela que pode ser interpretada como a relação sexual; a mítica, que diz a respeito da fertilidade da natureza; e a metalingüística, a função de decifração que toda leitura é como uma busca rumo ao inesperado e à rica interpretação que pode ter uma poesia.

A terra fértil é uma figura do tema da fecundação, afirmação máxima do valor de vida que melhor sintetiza o poema, pois nesta há a união da umidade da água com a secura da terra, matéria então viscosa, fertilidade que seduz e deixa sua marca.

O "oráculo" alude ao órgão genital feminino como um templo passível de culto, onde acontecem rituais e, nesse caso, a relação sexual é concebida como mística. Todo o poema pode ser entendido como um momento de imersão, de embriaguez devido à descrição do encharcamento na umidade, nos deltas, como rio que desemboca sua água que é origem para outro rio.

Essa imagem do movimento de um rio pode ser uma metáfora da ejaculação masculina, pois o sêmen advindo do órgão sexual é fértil, símbolo de vida, do gozo e do prazer descrito.

As costas são descritas como lúbricas e o suor sensual é dito "cieno bullente" como irradiação de calor e ebulição das sensações de prazer que cada um deles tem. $\mathrm{O}$ teor de fecundidade da relação sexual se expande para cada pedaço do corpo dos amantes, as costas são comparadas a terreno fértil e temos, deste modo, a imagem do suor fertilizando a pele como se fosse o movimento do fenômeno natural da chuva sobre a terra, já que o suor representa vida ativa e as costas a passividade da amante durante o ritual da relação com o outro.

$\mathrm{O}$ ato de decifrar pode ser compreendido como referência a desvendar o mistério da vida, a origem do ser. A intimidade do momento do coito para o sujeito é o que há de primordial e corriqueiro para a continuação da espécie e ao mesmo tempo é sublime por toda embriaguez que causa. A fecundidade proveniente do campo sêmico deste discurso faz com que ele mesmo se projete como duradouro.

Os blastos, parte do embrião que se desenvolve por efeito da germinação, estão onde se encontram os agouros e as siglas que precisam ser decodificadas, pois estão 
ocultas e são férteis, passíveis de fecundação por todo o prazer e gozo suscitados por meio da relação sexual dos amantes.

No final do poema temos "las libaciones", ato de derramar uma bebida com a finalidade religiosa de um ritual em honra a um deus ou divindade. Esta referência é colocada como parte da incursão do homem no prazer com sua amante já que o ato sexual é abordado como algo que marca, que é único a cada vez que se dá, gera prazer que deixa rastros como a ejaculação, o gozo.

Por fim, há os fervedouros representando o calor que descreve o contato físico de cunho sensual como o ápice do valor de vida, da fervência de um líquido e de agitação íntima na qual o gozo não é súbito, há um caminho de sedução o qual foi percorrido.

Elementos do mundo natural são citados constantemente de modo que adquirem novo sentido já que há a mistura do mineral com o vegetal e o animal, como nova possibilidade de percepção da realidade

A umidade cifrada é dita entre parênteses que indicam acréscimo de informações e índice de confidência, contemplam descrições minuciosas que intensificam a ação descrita. $\mathrm{O}$ poema pode ser lido até o fim e depois recomeçado sem pausa como continuação de um ciclo, de um ritual, do mesmo modo que é dita a experiência sexual descrita.

O discurso todo é uma sequiência de elementos figurados de modo direto, sob a forma sensorial "oigo tu cuerpo" e conceitual "la humedad cifrada". Há a alteração do significado comum das palavras que resulta um sentido geral expressivo e um sentido figurado em cada parte como contribuinte para o efeito poético.

Não há rima regular e a colocação de parênteses nos versos é feita de forma pouco convencional de modo a enfatizar os termos que abrangem. A pontuação também é feita de forma inovadora, pois algumas vezes não há ponto final no término dos períodos, apenas inicia-se outro no qual a palavra inicial tem letra maiúscula. Deste modo, o discurso linear é abalado pelo uso dos sinais gráficos diferenciados, como o travessão e os parênteses, os quais influenciam

A poetisa se valeu de imagens, figurações de sentido que fazem as palavras abrangerem significados além de seu limitado campo semântico. No corpus, as metáforas se dão em um processo de imagens concatenadas que confirmam o sentido mítico-metalingüístico do ato sexual.

\section{REFERÊNCIAS BIBLIOGRÁFICAS}

BARROS, Diana Luz Pessoa de. Teoria do discurso: fundamentos semióticos. São Paulo: Humanitas, 2001.

. Teoria semiótica do texto. São Paulo, Ática, 1990.

BERTRAND, Denis. Caminhos da semiótica literária. Tradução do Grupo CASA. Bauru: EDUSC, 2003.

DANIEL, Cláudio (org.). Jardim de Camaleões: a poesia neobarroca na América Latina. São Paulo: Iluminuras, 2004.

FIORIN, José Luiz. Elementos de análise do discurso. São Paulo: Contexto, 2005.

GREIMAS Algirdas Julien \& COURTÉS, Joseph. Dicionário de semiótica. São Paulo: Cultrix, s/d. 
JAKOBSON, Roman. Lingüística. Poética. Cinema. São Paulo: Perspectiva, 2004.

RASTIER, F. "Sistemática das isotopias". In: GREIMAS, A. J. (org.). Ensaios de semiótica poética. São Paulo: Cultrix/EDUSP, 1975.

ZILBERBERG, Claude. Razão e poética do sentido. São Paulo: EDUSP, 2006.

\section{ANEXOS}

\section{EN LA HUMEDAD CIFRADA - Coral Bracho}

Oigo tu cuerpo con la avidez abrevada y tranquila

de quien se impregna (de quien

emerge,

de quien se extiende saturado,

recorrido

de esperma) en la humedad

cifrada (suave oráculo espeso; templo)

en los limos, embalses tíbios, deltas,

de su origen; bebo

(tus raíces abiertas y penetrables; en tus costas

lascivas - cieno bullente - landas)

los designios musgosos, tus savias densas

(parva de lianas ebrias) Huelo

en tus bordes profundos, expectantes, las brasas,

en tus selvas untuosas,

las vertientes. Oigo (tu semen táctil) los veneros, las larvas;

(ábside fértil) Toco

en tus ciénagas vivas, en tus lamas; los rastros en tu fragua

envolvente: los indicios

(Abro

a tu muslos ungidos, rezumantes; escanciados de luz) Oigo

en tus légamos agrios, a tu orilla: los palpos, los augurios

- siglas inmersas; blastos -. En tus atrios:

las huellas vítreas, las libaciones (glebas fecundas),

los hervideros.

NA UMIDADE CIFRADA (Tradução do poeta Claudio Daniel)

Ouço teu corpo com a avidez saciada e tranqüila

de quem se impregna (de quem

emerge,

de quem se estende saturado,

percorrido

de esperma ) na umidade

cifrada (suave oráculo espesso; templo)

nos limos, açudes tíbios, deltas,

de sua origem; bebo 
( tuas raízes abertas e penetráveis; em tuas costas

lascivas - lodo fervente- landas)

os desígnios musgosos, tuas seivas densas

(rol de lianas ébrias) Aspiro

em tuas margens profundas, expectantes, as brasas,

em tuas selvas untuosas,

as vertentes. Ouço (teu sêmen táctil) as fontes, as larvas;

(abside fértil) Toco

em teus vivos lodaçais, em tuas lamas: os rastros em tua frágua

envolvente: os indícios

(Abro

tuas coxas ungidas, ressudantes, escanceadas de luz) Ouço

em teus ásperos barros, a tua borda: os palpos, os augúrios

- siglas imersas; blastos-. Em teus átrios:

as trilhas vítreas, as libações (glebas fecundas),

os fervedouros.

\section{Como citar este artigo:}

GUIRADO, Natália Cipolaro. Análise semiótica do poema "Em la humedad cifrada", de Coral Bracho. Estudos Semióticos. [online] Disponível na Internet via WWW.URL: http://www.fflch.usp.br/dl/semiotica/es. Editor Peter Dietrich. Número 4, São Paulo, 2008. Acesso em "dia/mês/ano". 